\title{
Executive dysfunction in children affected by obstructive sleep apnea syndrome: an observational study
}

This article was published in the following Dove Press journal:

Neuropsychiatric Disease and Treatment

8 August 2013

Number of times this article has been viewed

\author{
Maria Esposito' \\ Lorenzo Antinolfi' \\ Beatrice Gallai \\ Lucia Parisi ${ }^{3}$ \\ Michele Roccella ${ }^{3}$ \\ Rosa Marotta ${ }^{4}$ \\ Serena Marianna Lavano ${ }^{4}$ \\ Giovanni Mazzotta ${ }^{5}$ \\ Francesco Precenzano' \\ Marco Carotenuto' \\ 'Sleep Clinic for Developmental \\ Age, Clinic of Child and Adolescent \\ Neuropsychiatry, Department \\ of Mental and Physical Health \\ and Preventive Medicine, Second \\ University of Naples, Naples, Italy; \\ ${ }^{2}$ Unit of Child and Adolescent \\ Neuropsychiatry, University of \\ Perugia, Perugia, Italy; ${ }^{3}$ Child \\ Neuropsychiatry, Department of \\ Psychology, University of Palermo, \\ Palermo, Italy; ${ }^{4}$ Department of \\ Psychiatry, Magna Graecia University \\ of Catanzaro, Catanzaro, Italy; \\ ${ }^{5}$ Unit of Child and Adolescent \\ Neuropsychiatry, AUSL Umbria 2, \\ Terni, Italy
}

Correspondence: Maria Esposito Sleep Clinic for Developmental Age, Clinic of Child and Adolescent Neuropsychiatry, Department of Mental Health, Physical, and Preventive Medicine, Second University of Naples, Via Sergio Pansini 5 PAD XI, 80I 3 I Naples, Italy

$\mathrm{Tel}+398$ I566 6988

$\mathrm{Fax}+398 I 5666694$

Email maria.esposito2@unina2.it
Introduction: The role of sleep in cognitive processes can be considered clear and well established. Different reports have disclosed the association between sleep and cognition in adults and in children, as well as the impact of disturbed sleep on various aspects of neuropsychological functioning and behavior in children and adolescents. Behavioral and cognitive dysfunctions can also be considered as related to alterations in the executive functions $(\mathrm{EF})$ system. In particular, the EF concept refers to self-regulatory cognitive processes that are associated with monitoring and controlling both thought and goal directed behaviors. The aim of the present study is to assess the impact of the obstructive sleep apnea syndrome (OSAS) on EF in a large sample of school aged children.

Materials and methods: The study population comprised 79 children ( 51 males and 28 females) aged 7-12 years (mean $9.14 \pm 2.36$ years) with OSAS and 92 healthy children (63 males and 29 females, mean age $9.08 \pm 2.44$ years). To identify the severity of OSAS, an overnight respiratory evaluation was performed. All subjects filled out the Italian version of the Modified Card Sorting Test to screen EFs. Moreover, to check the degree of subjective perceived daytime sleepiness, all subjects were administered the Pediatric Daytime Sleepiness Scale (PDSS).

Results: No significant differences between the two study groups were found for age $(P=0.871)$, gender $(P=0.704)$, z-score of body mass index $(P=0.656)$, total intelligence quotient $(P=0.358)$, and PDSS scores $(P=0.232)$. The OSAS children showed a significantly higher rate of total errors $(P<0.001)$, perseverative errors $(P<0.001)$, nonperseverative errors $(P<0.001)$, percentage of total errors $(P<0.001)$, percentage of perseverative errors $(P<0.001)$, and percentage of nonperseverative errors $(P<0.001)$. On the other hand, OSAS children showed a significant reduction in the number of completed categories $(P=0.036)$, total correct sorts $(P=0.001)$, and categorizing efficiency $(P<0.001)$. The Pearson's correlation analysis revealed a significant positive relationship between all error parameters and apnea-hypopnea index, oxygen desaturation index, and percentage of mean desaturation of $\mathrm{O}_{2}$ with a specular negative relationship between the error parameters and the mean oxygen saturation values, such as a significant negative relationship between apnea-hypopnea index, oxygen desaturation index, percent of mean desaturation of $\mathrm{O}_{2}$, and the number of completed categories.

Conclusion: Our study identified differences in the executive functioning of children affected by OSAS and is the first to identify a correlation between alteration in respiratory nocturnal parameters and EF that has not yet been reported in developmental age. These findings can be considered as the strength and novelty of the present report in a large pediatric population.

Keywords: OSAS, polysomnography, executive functions, sleep, sleepiness, children

\section{Introduction}

The role of sleep in cognitive processes can be considered as clear and well established. ${ }^{1-5}$ In general, a good sleep may be considered as a strong predictor of 
a good health, ${ }^{6,7}$ and conversely, a disturbed and/or interrupted sleep would be accompanied by many alterations in all aspects of life, in both genders and at all ages. ${ }^{8,9}$ In fact, sleep plays a key role for daytime functioning and neurocognitive performance in childhood and adolescence, ${ }^{10}$ probably promoting and/or influencing the neural plasticity process and enhancing memory consolidation during life. ${ }^{11}$ Different reports have disclosed the association between sleep and cognition in adults and children, ${ }^{4,5,12,13}$ as well as the impact of disturbed sleep on various aspects of neuropsychological functioning and behavior in children and adolescents. ${ }^{14}$ Moreover, the impact on cognitive and behavior control linked to sleep disruption is well documented in adults affected by obstructive sleep apnea syndrome (OSAS), ${ }^{15-17}$ and by periodic limb movement disorder. ${ }^{18,19}$

Behavioral and cognitive dysfunctions can be considered to be related to alteration in the executive functions (EF) system. In particular, the EF concept refers to self-regulatory cognitive processes that are associated with monitoring and controlling both thought and goal directed behaviors. ${ }^{20,21}$ EF domains include (1) inhibitory control (suppression of actions that are inappropriate in a given context and that interfere with a goal driven behavior), (2) attention (the ability to maintain a consistent behavioral response during continuous and repetitive activity) and the closely related concept of mental flexibility (disengagement of an irrelevant task set and subsequent engagement of a relevant task set despite interference and/or priming), (3) reward sensitivity (the relative dominance of the behavioral activation system driving motivated behavior associated with risk taking behavior), and (4) working memory (active maintenance and flexible updating of goal/task relevant information with limited capacity). ${ }^{20}$

On the other hand, several studies have shown that children aged 3-5 years undergo a significant and rapid development in EF until adolescence. ${ }^{22,23}$ Moreover, the prefrontal cortex is closely associated with executive functioning and may be considered as the last region of the brain to mature, with an improvement in each dimension of EF (eg, inhibition, shifting, and working memory). ${ }^{24}$ At the same time, the EF system can be considered as quite vulnerable to a specific stressor such as altered/disturbed sleep due to respiratory troubles during childhood. To the best of our knowledge, there are few studies about the correlation between nocturnal respiratory parameters and executive functioning in childhood. ${ }^{25-29}$ Therefore, the aim of the present study is to assess the impact of OSAS on EF in a large sample of school aged children.

\section{Materials and methods}

\section{Participants}

The study population comprised 79 children (51 males and 28 females) aged $7-12$ years (mean $9.14 \pm 2.36$ years) with OSAS recruited to the Sleep Center for Developmental Age of Child and Adolescent Neuropsychiatry Department of Second University of Naples. Exclusion criteria were psychiatric illness (ie, schizophrenia, psychosis, attention deficit hyperactivity disorder, depressive symptoms), mental retardation (IQ < 75), neurological disorder (epilepsy, neuromuscular disorders, cerebral palsy), overweight (body mass index $(\mathrm{BMI}) \geq 85$ th percentile) or obesity $(\mathrm{BMI} \geq 95$ th percentile), ${ }^{30}$ and referral for sleep complaints other than OSAS. The control group consisted of 92 healthy children (63 males and 29 females, mean age $9.08 \pm 2.44$ years) enrolled in schools within the Campania region.

The subjects in both groups were recruited from the same urban area; participants were all Caucasian, and held a middle class socioeconomic status (between class 2 or class 3 corresponding to 28,000-55,000 Euros/year to 55,000-75,000 Euros/year, respectively, according to the current Italian economic legislation parameters) as previously reported. ${ }^{31}$ All evaluations were performed after informed parental consent was obtained for all the children enrolled,

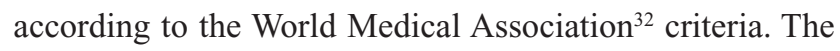
study was approved by the Departmental Ethics Committee at the Second University of Naples.

\section{Cognitive assessment}

Intellective functioning was assessed by the Italian version of the Wechsler Intelligence Scale for Children (WISC)-III edition $^{33,34}$ which is applicable for children ranging in age from 6 to 16 years. The WISC-III is composed of 13 distinct subtests divided into two scales, a verbal scale and a performance scale. The six verbal scale tests use language based items, whereas the seven performance scales use visual motor items that are less dependent on language. Five of the subtests in each scale produce scale-specific intelligence quotients (IQs) such as verbal IQ and performance IQ, and the ten subtest scores produce a total scale IQ (Total IQ), ranging from 85 to 115 in normal subjects.

\section{Executive functions evaluation}

To assess the EF in the entire sample group, the Italian version of the Modified Card Sorting Test (MCST) was administered according to the validation criteria for developmental age. ${ }^{35}$ The MCST is a card sorting task that is designed to assess EF such as cognitive flexibility, attention shifting, and set 
maintenance and has been found to be efficacious for use with young children. ${ }^{35}$ After each MCST administration, we calculated all subscores that were identified across MCST literature. We first determined if a participant's errors were perseverative or nonperseverative. As recommended by Nelson, ${ }^{36}$ we classified perseverative errors when participants persisted to sort according to previous criteria after receiving feedback that a sort was incorrect. All other errors were classified as non-perseverative.

Once errors were classified, we calculated the following scores for each participant: the number of completed categories (CAT), total errors (TE), perseverative errors (PE), nonperseverative errors (NPE), total correct sorts (CS), the percentage of total errors that were perseverative $(\% \mathrm{PE})$, the percentage of total errors that were nonperseverative ( $\% \mathrm{NPE})$, and failures to maintain set (FMS), which were defined as instances when participants make at least three consecutive correct responses (ie, 50\%) needed to complete a category but make an error before successful completion. According to the criteria for developmental age, supplementary scores were derived, ${ }^{35}$ such as the percentage of TE (\%TE) and the categorizing efficiency (CE), by taking into account the number of cards used by the subject to complete a maximum of six categories. This score ranges from 0 to 48 . For each item, the age related $\mathrm{T}$ scores were considered for the analyses.

In summary, according to the MCST scoring criteria, higher scores demonstrate better performances for the following parameters: CAT, CS, CE; lower scores show better performances for the following parameters: TE, \% TE, PE, $\% \mathrm{PE}, \mathrm{NPE}, \% \mathrm{NPE}$, and failures to maintain set.

\section{Pediatric daytime sleepiness evaluation}

As reported in a study, ${ }^{37}$ to check the degree of subjective perceived daytime sleepiness, all subjects were administered the Pediatric Daytime Sleepiness Scale (PDSS). ${ }^{38}$ The PDSS is an eight item, self-reported Likert-type questionnaire that measures daytime sleepiness in school age populations, with possible scores ranging from 0 to 32 . Higher PDSS scores indicate greater daytime sleepiness. Along with being easy to administer, score, and interpret, the PDSS has a high internal consistency $(\alpha)$ of at least 0.80 in split-half samples and acceptable factor loadings $(0.4) .^{38}$

\section{Sleep evaluation}

In all children (with or without OSAS) a cardiorespiratory device (Embletta X10; Embletta PDS, MedCare Flaga, Iceland) was used to perform an overnight respiratory evaluation. ${ }^{9,39,40}$ The Embletta device is used to specifically detect the presence of OSAS and to assess its severity, is suitable for use both in a sleep laboratory and at home, ${ }^{41}$ has been validated against full polysomnography for the evaluation of nocturnal breathing disorders, ${ }^{42}$ and is largely used in the pediatric age group. ${ }^{39,40}$ All evaluations were performed overnight in the sleep laboratory at the Sleep Center for Developmental Age of Child and Adolescent Neuropsychiatry at the Second University of Naples. All recordings started at the subjects' usual bedtime and continued until spontaneous morning awakening.

The parameters measured were: nasal airflow using two appropriately placed thermistors (one thermistor for oral breath and the other for nasal breath), thoracoabdominal movements via two piezoelectric bands, pulse oximetry using a finger probe, snoring episodes detected via a vibration sensor placed anterior to the sternocleidomastoid muscle, and continuous actigraphy to monitor and record body position. Recordings were analyzed manually using the device-specific software (Somnologica for Embletta 3.3; Embla, Broomfield, CO, USA). Sleep onset was estimated as the beginning of the first 10 -minute period not containing any changes in body position and morning awakening was estimated as the end of the last such 10-minute period. ${ }^{43}$ Estimated sleep time was calculated as the time between sleep onset and morning awakening. Recordings were analyzed for artefactual or uninterpretable periods of nasal flow, thoracic effort, abdominal effort, or oximetry. Movement periods and artefactual or uninterpretable periods were excluded from the estimated sleep time if they lasted for more than 5 minutes, and the corrected estimated sleep time was calculated. ${ }^{43}$ A minimum of 5 hours of corrected estimated sleep time was required.

All the recordings were visually scored by one of the investigators (MC) according to pediatric criteria. ${ }^{44-47}$ Specifically, obstructive apnea was defined as cessation of airflow, lasting for at least two breaths, in the presence of paradoxical ribcage and abdominal movements. The hypopnea index was defined as a reduction in the nasal flow curve signal by more than $50 \%$ that was accompanied by either oxygen desaturation or arousal. Central apnea was defined as the absence of airflow at both the nose and mouth with absent inspiratory effort throughout the duration of the event, lasting 20 seconds or longer, or two missed breaths accompanied by at least 3\% oxygen desaturation, an arousal, or an awakening. The apnea-hypopnea index (AHI) was defined as the number of obstructive apneas and hypopneas per hour of sleep, ${ }^{44,45,48}$ and the lowest oxygen saturation value and number of desaturation events by $4 \%$ and to $90 \%$ 
were counted. The oxygen desaturation index (ODI), defined as events per hour, was also calculated. An AHI and ODI $\leq 1$ per hour were considered as normal according to American Thoracic Society criteria. ${ }^{44,45}$

\section{Statistical analysis}

Comparisons between age, gender, z-score of BMI (z-BMI), intellectual abilities, MCST, PDSS, and respiratory parameters obtained in OSAS children and typical developing individuals were carried out by the $t$-test. To verify the matching sex ratio $(\mathrm{M} / \mathrm{F})$, the Chi-squared test was performed. $P<0.05$ was considered statistically significant. The Pearson's correlation test was computed to analyze the relationship among MCST scores with respiratory indices (AHI and ODI). The commercially available data analysis software STATISTICA version 6 (StatSoft, Inc, Tulsa, OK, USA) was used for all statistical tests.

\section{Results}

No significant differences between the two study groups were found for age $(P=0.871)$, gender $(P=0.704), \mathrm{z}-\mathrm{BMI}$ $(P=0.656)$, Total IQ $(P=0.358)$, and PDSS scores $(P=0.232)$ (Table 1). Table 2 shows the differences in nocturnal respiratory parameters and MCST scores between the two groups. The OSAS children showed a significantly higher quota of TE $(P<0.001)$, PE $(P<0.001)$, NPE $(P<0.001)$, \% TE $(P<0.001), \%$ PE $(P<0.001)$, and \%NPE $(P<0.001)$. On the other hand, OSAS children showed a significant reduction in the number of CAT $(P=0.036)$, total CS $(P=0.001)$, and $\mathrm{CE}(P<0.001)$ (Table 2$)$. Moreover, the Pearson's correlation analysis revealed a significant positive relationship between all error parameters and AHI, ODI, and percentage of mean desaturation of $\mathrm{O}_{2}$ with a specular negative relationship between the error parameters and the mean oxygen

Table I Characteristics of children affected by OSAS and controls

\begin{tabular}{llll}
\hline & $\begin{array}{l}\text { OSAS } \\
(\mathbf{N}=\mathbf{7 9})\end{array}$ & $\begin{array}{l}\text { Normal } \\
\mathbf{( N = 9 2 )}\end{array}$ & $\mathbf{P}$ \\
\hline Age & $9.14 \pm 2.36$ & $9.08 \pm 2.44$ & $0.87 \mathrm{I}$ \\
Sex ratio (M/F) & $5 \mathrm{I} / 28$ & $63 / 29$ & 0.704 \\
z-BMI & $0.6 \mathrm{I} \pm 0.27$ & $0.59 \pm 0.31$ & 0.656 \\
Total-IQ & $89.47 \pm 4.19$ & $90.16 \pm 5.4 \mathrm{I}$ & 0.358 \\
PDSS & $12.4 \mathrm{I} \pm 2.68$ & $1 \mathrm{I} .87 \pm 2.33$ & 0.232 \\
\hline
\end{tabular}

Notes: The t-test and Chi-square test, where appropriated, were applied. $P$ values $<0.05$ were considered statistically significant. Mean differences for age, sex, z-score Body Mass Index (z-BMI), Total Intelligence Quotient (Total IQ) and Pediatric Daytime Sleepiness Scale (PDSS) scores between the group of children affected by Obstructive Sleep Apnea Syndrome (OSAS) and group of typical developing children (Normal).
Table 2 Comparison of nocturnal respiratory indexes and MCST scores between the children affected by Obstructive Sleep Apnea Syndrome (OSAS) and typical developing children (Control)

\begin{tabular}{|c|c|c|c|}
\hline & $\begin{array}{l}\text { OSAS } \\
(N=79)\end{array}$ & $\begin{array}{l}\text { Control } \\
(\mathrm{N}=92)\end{array}$ & $P$ \\
\hline $\mathrm{AHI}$ & $9.914 \pm 3.216$ & $0.482 \pm 0.302$ & $<0.001$ \\
\hline ODI & $5.041 \pm 1.762$ & $0.481 \pm 0.372$ & $<0.001$ \\
\hline Mean $\mathrm{SpO}_{2}(\%)$ & $94.06 \mathrm{I} \pm 1.243$ & $98.735 \pm 0.649$ & $<0.001$ \\
\hline $\begin{array}{l}\text { Mean } \mathrm{SpO}_{2} \\
\text { desaturation (\%) }\end{array}$ & $5.918 \pm 1.087$ & $0.948 \pm 0.65 I$ & $<0.001$ \\
\hline CAT & $53.948 \pm 9.349$ & $56.381 \pm 5.156$ & 0.036 \\
\hline CS & $48.827 \pm 8.718$ & $52.972 \pm 8.014$ & 0.001 \\
\hline CE & $46.148 \pm 9.036$ & $50.906 \pm 5.783$ & $<0.001$ \\
\hline TE & $42.062 \pm 8.162$ & $36.081 \pm 2.053$ & $<0.001$ \\
\hline$\% \mathrm{TE}$ & $43.327 \pm 8.912$ & $34.918 \pm 4.053$ & $<0.001$ \\
\hline PE & $47.436 \pm 13.208$ & $36.024 \pm 2.739$ & $<0.001$ \\
\hline$\% \mathrm{PE}$ & $47.914 \pm 13.895$ & $38.766 \pm 5.419$ & $<0.001$ \\
\hline NPE & $41.093 \pm 7.086$ & $37.481 \pm 3.244$ & $<0.001$ \\
\hline$\%$ NPE & $31.189 \pm 13.053$ & $23.046 \pm 4.735$ & $<0.001$ \\
\hline FMS & $47.073 \pm 13.992$ & $45.191 \pm 3.718$ & 0.216 \\
\hline
\end{tabular}

Note: $t$-Test was applied and $P$ values $<0.05$ were considered statistically significant. Apnea/hypopnea index-AHI; Oxygen desaturation index-ODI; percentage of $\mathrm{SpO}_{2}$ mean saturation-Mean $\mathrm{SpO}_{2}$ [\%]; percentage of $\mathrm{SpO}_{2}$ mean desaturation-Mean $\mathrm{SpO}_{2}$ desaturation [\%]; number of completed categories-CAT; total correct sorts-CS; categorizing efficiency-CE; total errors-TE; percentage of total errors-\%TE; perseverative errors-PE; percentage of total errors that were perseverative-\% $\mathrm{PE}$; non-perseverative errors-NPE; percentage of total errors that were nonperseverative-\%NPE; failures to maintain set-FMS.

saturation values, such as a significant negative relationship between AHI, ODI, percentage of mean desaturation of $\mathrm{O}_{2}$, and the number of CAT (Table 3 ).

\section{Discussion}

The main findings of our study can be summarized in that children affected by OSAS presented a lower executive functioning, as showed by the MCST evaluation, with a significant correlation with the severity of nocturnal respiratory impairment. In general, the most common documented cause of sleep related breathing disorders in children can be considered as upper airway obstruction, with prevalence for OSAS of about $1 \%-3 \%$, and a peak prevalence between 2 and 8 years of age. ${ }^{49}$ The symptoms of OSAS include abnormal position during sleep, ${ }^{50-52}$ mood disorders,, $93-56$ reduced quality of life, and cognitive problems ${ }^{57}$ at all ages. Moreover, considering the increasing prevalence of OSAS and neurocognitive and cardiovascular consequences, an objective evaluation with nocturnal monitoring for children with suspected OSAS has been recommended. ${ }^{58,59}$

Cognitive impairment in subjects affected by OSAS has been studied since the $1980 \mathrm{~s},{ }^{60}$ and the most common cognitive deficits reported in most adults were in attention or concentration, vigilance, memory and learning abilities, motor 
Table 3 Correlation between nocturnal respiratory indexes and MCST scores in our study sample

\begin{tabular}{lllll}
\hline & AHI & ODI & $\begin{array}{l}\text { Mean } \\
\mathrm{SpO}_{2}(\%)\end{array}$ & $\begin{array}{l}\text { Mean } \mathrm{SpO}_{2} \\
\text { desaturation (\%) }\end{array}$ \\
\hline CAT & $-\mathbf{0 . 3 5 2 8}$ & $-\mathbf{0 . 1 8 5 0}$ & $\mathbf{0 . 2 1 2 2}$ & $-\mathbf{0 . 2 8 2 8}$ \\
CS & 0.0753 & 0.0339 & -0.0193 & $\mathbf{0 . 2 0 3 9}$ \\
CE & 0.0325 & 0.1230 & -0.0620 & 0.1249 \\
TE & $\mathbf{0 . 4 7 4 5}$ & 0.1374 & $-\mathbf{0 . 2 6 0 2}$ & $\mathbf{0 . 5 0 0 0}$ \\
$\%$ TE & $\mathbf{0 . 5 1 6 7}$ & $\mathbf{0 . 2 5 1 7}$ & $-\mathbf{0 . 2 4 8 5}$ & $\mathbf{0 . 5 3 1 4}$ \\
PE & $\mathbf{0 . 4 1 8 3}$ & $\mathbf{0 . 2 1 0 0}$ & $-\mathbf{0 . 3 6 0 3}$ & $\mathbf{0 . 4 1 1 4}$ \\
$\%$ PE & $\mathbf{0 . 3 7 8 7}$ & $\mathbf{0 . 1 8 8 0}$ & $-\mathbf{0 . 3 1 2 3}$ & $\mathbf{0 . 3 6 6 0}$ \\
NPE & $\mathbf{0 . 3 5 2 9}$ & $\mathbf{0 . 1 9 1 0}$ & -0.0176 & $\mathbf{0 . 4 2 2 0}$ \\
$\%$ NPE & $\mathbf{0 . 4 1 9 9}$ & $\mathbf{0 . 2 1 9 8}$ & $-\mathbf{0 . 1 6 3 6}$ & $\mathbf{0 . 4 6 4 3}$ \\
FMS & $\mathbf{0 . 2 0 8 6}$ & $\mathbf{0 . 0 3 5 3}$ & $-\mathbf{0 . 1 6 2 0}$ & 0.0346 \\
\hline
\end{tabular}

Notes: Pearson's correlation test was computed. $P$ values $<0.05$ are reported in bold characters. Apnea/hypopnea index-AHI; Oxygen desaturation index-ODI; percentage of $\mathrm{SpO}_{2}$ mean saturation-Mean $\mathrm{SpO}_{2}$ [\%]; percentage of $\mathrm{SpO}_{2}$ mean desaturation-Mean $\mathrm{SpO}_{2}$ desaturation [\%]; number of completed categories-CAT; total correct sorts-CS; categorizing efficiency-CE; total errors-.TE; percentage of total errors-\%TE; perseverative errors-PE; percentage of total errors that were perseverative-\%PE; non-perseverative errors-NPE; percentage of total errors that were non-perseverative-\%NPE; failures to maintain set-FMS

performance, constructional abilities, and EF. Both excessive daytime sleepiness and nocturnal hypoxemia seem to equally contribute to cognitive deficits. ${ }^{60-62}$ Moreover, excessive daytime sleepiness has been mostly related to impairment in attention, vigilance, and memory function, while hypoxemia tends to correlate with deficits in EF. ${ }^{57,61}$ In this light, our findings are suggestive for a causative role of nocturnal hypoxemia in executive impairment, considering that the levels of subjective perceived daytime sleepiness are comparable with the normal control subjects $(P=0.232)$. Only about $7 \%$ of children affected by OSAS present with symptoms that are compatible with excessive daytime sleepiness. ${ }^{63}$

Alternatively, several studies have reported a nonlinear worsening in cognitive impairment related to the severity of OSAS, ${ }^{64,65}$ different from our report of the positive and significant relationships between executive functioning and nocturnal respiratory parameters (AHI, ODI, and mean oxygen desaturation levels) and a negative correlation with the mean oxygen saturation level (Table 3).

With respect to the other few studies in a pediatric population, our results can be considered quite different. In fact, Archbold et al in $2004^{25}$ and Kohler et al in $2009^{29}$ both reported the effect of adenotonsillectomy on executive functioning, with no significant correlation with nocturnal respiratory parameters. On the other hand, Beebe et al failed to indicate any clear relationship between neuropsychological functioning and objective indices of hypoxia or sleep disruption in a small sample of children, ${ }^{26}$ similar to a report by O'Brien et al. ${ }^{27}$ This report cannot be considered as properly focused on executive functioning evaluation in children affected by sleep related breathing disorders (SRBD) because the authors considered the effect of the sleep pressure score linked and due to the SRBD on behavior and on generic neuropsychological functioning. Finally, according to Calhoun et al in $2009^{28}$ no clear relationship between neuropsychological functioning and objective indices of hypoxia or sleep disruption was identified.

Furthermore, as reported in a study, the MCST evaluation results may be considered to be related to changes in blood flow levels, particularly in the frontal cortex and in the hippocampus regions. ${ }^{66}$ In this perspective, our results suggest a putative relationship between the executive efficiency of the frontal lobes and the severity of night breathing alterations as shown by the correlation between high AHI and ODI values and the increase in MCST error rates (PE and NPE). On the other hand, gray matter reduction level in the frontalparietal and in the hippocampus regions ${ }^{67,68}$ may explain the perseveration tendency in our OSAS children that is related to their respiratory nocturnal abnormalities.

Alternatively, our results also support the hypothesis that the deficit in executive functioning may be related primarily to the severity of nocturnal hypoxemia rather than daytime sleepiness ${ }^{69,70}$ in children, although further studies are needed. Moreover, the neurocognitive deficits in domains such as manual skills, planning abilities, and in particular, executive functioning, do not seem to improve after continuous positive airway pressure (CPAP) treatment ${ }^{71,72}$ in adults, suggesting that OSAS related hypoxemia resulted in permanent brain injury leading to enduring cognitive deficits. In fact, studies ${ }^{71,72}$ evaluating cognitive functioning in OSAS patients seem to suggest that CPAP improves only some cognitive functions, with long-term cognitive deficits most pronounced for executive functioning. On the other hand, in adult patients with untreated OSAS, the impact on verbal and intellectual functioning was minimal, irrespective of vigilance and executive functioning impairment. ${ }^{73}$ In this light, our finding would suggest the importance of EF assessment in children affected by OSAS, and the need for an early rehabilitation and ventilatory therapy to avoid establishment of permanent executive functioning damage.

In conclusion, the following limitations of this study need to be taken into account: (1) subjects were recruited from a specific region in southern Italy (and cannot be considered as derived by the whole Italian pediatric population), (2) our data was derived from a nocturnal cardiorespiratory evaluation and not from full polysomnography (with a lack of correlation with the sleep stages percentages), (3) assessment of the excessive daytime sleepiness was not performed using objective methods such as 
the Multiple Latency Sleep Test, (4) this can be considered as an observational resting study on a small sample of children affected by OSAS, (5) follow-up data was not available, and (6) neuroimaging evaluations were not performed.

However, our study does identify differences in executive functioning in children affected by OSAS and is the first to identify a correlation between alteration in respiratory nocturnal parameters and EF not yet reported in the developmental age group, and these findings can be considered as the strength and novelty of the present report in a large pediatric population.

\section{Acknowledgment}

The authors wish to thank all the children and their families who participated in this study.

\section{Disclosure}

The authors report no conflicts of interest in this work. None of the authors have any personal, financial support, or involvement with organizations that hold financial interest in the subject matter.

\section{References}

1. Jackson ML, Gunzelmann G, Whitney P, et al. Deconstructing and reconstructing cognitive performance in sleep deprivation. Sleep Med Rev. 2013;17(3):215-225.

2. Ferrara M, Moroni F, De Gennaro L, Nobili L. Hippocampal sleep features: relations to human memory function. Front Neurol. 2012;3:57.

3. McCoy JG, Strecker RE. The cognitive cost of sleep lost. Neurobiol Learn Mem. 2011;96(4):564-582.

4. Esposito M, Carotenuto M. Intellectual disabilities and power spectra analysis during sleep: a new perspective on borderline intellectual functioning. J Intellect Disabil Res. In press. 2013 doi: 10.1111/jir.12036.

5. Esposito M, Carotenuto M. Borderline intellectual functioning and sleep: the role of cyclic alternating pattern. Neurosci Lett. 2010;19; 485(2):89-93.

6. Luyster FS, Strollo PJ Jr, Zee PC, et al; Boards of Directors of the American Academy of Sleep Medicine and the Sleep Research Society. Sleep: a health imperative. Sleep. 2012;1;35(6):727-734.

7. Whitton S. Nighty night sleep tight-health benefits of a good night's sleep. Insight. 2012;37(4):22.

8. Kallestad H, Hansen B, Langsrud K, et al. Impact of sleep disturbance on patients in treatment for mental disorders. BMC Psychiatry. 2012;29;12:179.

9. Carotenuto M, Esposito M, Parisi L, et al. Depressive symptoms and childhood sleep apnea syndrome. Neuropsychiatr Dis Treat. 2012;8:369-373.

10. Born J, Wilhelm I. System consolidation of memory during sleep. Psychol Res. 2012;76(2):192-203.

11. Curcio G, Ferrara M, De Gennaro L. Sleep loss, learning capacity and academic performance. Sleep Med Rev. 2006;10(5):323-337.

12. Bernier A, Beauchamp MH, Bouvette-Turcot AA, Carlson SM, Carrier J. Sleep and cognition in preschool years: specific links to executive functioning. Child Dev. Epub February 24, 2013.

13. Gagnon JF, Bertrand JA, Génier Marchand D. Cognition in rapid eye movement sleep behavior disorder. Front Neurol. 2012;3:82.

14. Kopasz M, Loessl B, Hornyak M, et al. Sleep and memory in healthy children and adolescents - a critical review. Sleep Med Rev. 2010;14(3):167-177.
15. Ferini-Strambi L, Marelli S, Galbiati A, Castronovo C. Effects of continuous positive airway pressure on cognitive function and neuroimaging data in obstructive sleep apnea. Int J Psychophysiol. Epub April 6, 2013.

16. Lal C, Strange C, Bachman D. Neurocognitive impairment in obstructive sleep apnea. Chest. 2012;141(6):1601-1610.

17. Sforza E, Roche F. Sleep apnea syndrome and cognition. Front Neurol. 2012;3:87.

18. Richards KC, Roberson PK, Simpson K, et al. Periodic leg movements predict total sleep time in persons with cognitive impairment and sleep disturbance. Sleep. 2008;31(2):224-230.

19. Edinger JD. Cognitive and behavioral anomalies among insomnia patients with mixed restless legs and periodic limb movement disorder. Behav Sleep Med. 2003;1(1):37-53.

20. Pannacciulli N, Del Parigi A, Chen K, Le DS, Reiman EM, Tataranni PA. Brain abnormalities in human obesity: a voxel-based morphometric study. Neuroimage. 2006;31(4):1419-1425.

21. Carlson SM. Developmentally sensitive measures of executive function in preschool children. Dev Neuropsychol. 2005;28(2):595-616.

22. Espy KA, Kaufmann PM, Glisky ML. New procedures to assess executive functions in preschool children. Clin Neuropsychol. 2001;15(1):46-58.

23. Garon N, Bryson SE, Smith IM. Executive function in preschoolers: a review using an integrative framework. Psychol Bull. 2008;134(1): 31-60.

24. Arain M, Haque M, Johal L, et al. Maturation of the adolescent brain. Neuropsychiatr Dis Treat. 2013;9:449-461.

25. Archbold KH, Giordani B, Ruzicka DL, Chervin RD. Cognitive executive dysfunction in children with mild sleep-disordered breathing. Biol Res Nurs. 2004;5(3):168-176.

26. Beebe DW, Wells CT, Jeffries J, Chini B, Kalra M, Amin R. Neuropsychological effects of pediatric obstructive sleep apnea. $J$ Int Neuropsychol Soc. 2004;10(7):962-975.

27. O'Brien LM, Mervis CB, Holbrook CR, et al. Neurobehavioral correlates of sleep-disordered breathing in children. J Sleep Res. 2004;13(2): $165-172$.

28. Calhoun SL, Mayes SD, Vgontzas AN, Tsaoussoglou M, Shifflett LJ, Bixler EO. No relationship between neurocognitive functioning and mild sleep disordered breathing in a community sample of children. J Clin Sleep Med. 2009;5(3):228-234.

29. Kohler MJ, Lushington K, van den Heuvel CJ, Martin J, Pamula Y, Kennedy D. Adenotonsillectomy and neurocognitive deficits in children with sleep disordered breathing. PLoS one. 2009;4(10): e7343.

30. Cacciari E, Milani S, Balsamo A, et al. Italian cross-sectional growth charts for height, weight and BMI (2 to $20 \mathrm{yr}$ ). J Endocrinol Invest. 2006;29(7):581-593.

31. Esposito M, Verrotti A, Gimigliano F, Ruberto M, Agostinelli S, Scuccimarra G, Pascotto A, Carotenuto M. Motor coordination impairment and migraine in children: a new comorbidity?. Eur J Pediatr. 2012 Nov;171(11):1599-1604.

32. World Medical Association. World Medical Association Declaration of Helsinki: Ethical Principles for Medical Research Involving Human Subjects. Ferney-Voltaire: World Medical Association; 2008. Available from: http://www.wma.net/en/30publications/10policies/b3/. Accessed December 6, 2012.

33. Wechsler D. Wechsler Intelligence Scale for Children, 3rd ed. San Antonio: The Psychological Corporation; 1991.

34. Orsini A, Picone L. WISC III. Contributo alla taratura italiana Giunti O.S. Organizzazioni Speciali, Firenze 2006. Available from: URL http:// www.giuntios.it/it/catalogo/EI302. Accessed July 1, 2013.

35. Cianchetti C, Corona S, Foscoliano M, Contu D, Sannio-Fancello G. Modified Wisconsin Card Sorting Test (MCST, MWCST): normative data in children 4-13 years old, according to classical and new types of scoring. Clin Neuropsychol. 2007;3:456-478.

36. Nelson HE. A modified card sorting test sensitive to frontal lobe defects. Cortex. 1976;12:313-324. 
37. Esposito M, Roccella M, Parisi L, Gallai B, Carotenuto M. Hypersomnia in children affected by migraine without aura: a questionnaire-based case-control study. Neuropsychiatr Dis Treat. 2013;9:289-294.

38. Drake C, Nickel C, Burduvali E, Roth T, Jefferson C, Pietro B. The Pediatric Daytime Sleepiness Scale (PDSS): sleep habits and school outcomes in middle-school children. Sleep. 2003;26: 455-458.

39. Carotenuto M, Esposito M, Pascotto A. Facial patterns and primary nocturnal enuresis in children. Sleep Breath. 2011;15(2): 221-227.

40. Carotenuto M, Santoro N, Grandone A, et al. The insulin gene variable number of tandem repeats (INS VNTR) genotype and sleep disordered breathing in childhood obesity. J Endocrinol Invest. 2009;32(9): $752-755$.

41. Dingli K, Coleman EL, Vennelle M, et al. Evaluation of a portable device for diagnosing the sleep apnoea/hypopnoea syndrome. Eur Respir J. 2003;21(2):253-259.

42. Skinner MA, Choudhury MS, Homan SD, Cowan JO, Wilkens GT, Taylor DR. Accuracy of monitoring for sleep-related breathing disorders in the coronary care unit. Chest. 2005;127:66-71.

43. Moss D, Urschitz MS, von Bodman A, et al. Reference values for nocturnal home polysomnography in primary schoolchildren. Pediatr Res. 2005;58(5):958-965.

44. American Thoracic Society. Standards and indications for cardiopulmonary sleep studies in children. Am J Respir Crit Care Med. 1996;153(2):866-878.

45. Redline S, Budhiraja R, Kapur V, et al. The scoring of respiratory events in sleep: reliability and validity. J Clin Sleep Med. 2007;15;3(2) 169-200.

46. Marcus CL, Omlin KJ, Basinki DJ, et al. Normal polysomnographic values for children and adolescents. Am Rev Respir Dis. 1992;146(5 Pt 1):1235-1239.

47. Sleep-related breathing disorders in adults: recommendations for syndrome definition and measurement techniques in clinical research. The report of on American Academy of Sleep Medicine Task Force. Sleep. 1999;22(5):667-689.

48. Wong TK, Galster P, Lau TS, Lutz JM, Marcus CL. Reliability of scoring arousals in normal children and children with obstructive sleep apnea syndrome. Sleep. 2004;27(6):1139-1145.

49. Lumeng JC, Chervin RD. Epidemiology of pediatric obstructive sleep apnea. Proc Am Thorac Soc. 2008;5(2):242-252.

50. Kushida CA, Rao S, Guilleminault C, et al. Cervical positional effects on snoring and apneas. Sleep Res Online. 1999;2(1):7-10.

51. Pasterkamp H, Schäfer J, Wodicka GR. Posture-dependent change of tracheal sounds at standardized flows in patients with obstructive sleep apnea. Chest. 1996;110(6):1493-1498.

52. Carotenuto M, Gimigliano F, Fiordelisi G, Ruberto M, Esposito M. Positional abnormalities during sleep in children affected by obstructive sleep apnea syndrome: The putative role of kinetic muscular chains. Med Hypotheses. 2013 Aug;81(2):306-8.

53. Velasco-Rey MC, Sánchez-Muñoz M, Gutiérrez-López MI, Trujillo-Borrego A, Sánchez-Bonome L. Psychotic depression induced by Obstructive Sleep Apnoea Syndrome (OSAS): a case reported. Actas Esp Psiquiatr. 2012;40(1):43-45.

54. Ruberto M, Liotti F. Obstructive sleep apnoea syndrome (OSAS) and mood disorders in a population of public transport drivers. Med Lav. 2011;102(2):201-207. Italian [with English abstract].

55. Hattori M, Kitajima T, Mekata T, et al. Risk factors for obstructive sleep apnea syndrome screening in mood disorder patients. Psychiatry Clin Neurosci. 2009;63(3):385-391.
56. Saunamäki T, Jehkonen M. Depression and anxiety in obstructive sleep apnea syndrome: a review. Acta Neurol Scand. 2007;116(5): 277-288.

57. Brown WD. The psychosocial aspects of obstructive sleep apnea. Semin Respir Crit Care Med. 2005;26:33-43.

58. American Academy of Pediatrics, Section on pediatric Pulmonology, Subcommittee on Obstructive Sleep Apnea Syndrome. Clinical practice guideline: diagnosis and management of childhood obstructive sleep apnea syndrome. Pediatrics. 2002;109(4):704-712.

59. Brockmann PE, Schaefer C, Poets A, Poets CF, Urschitz MS. Diagnosis of obstructive sleep apnea in children: A systematic review. Sleep Med Rev. Epub January 29, 2013

60. Engleman H, Joe D. Neuropsychological function in obstructive sleep apnoea. Sleep Med Rev. 1999;3:59-78.

61. Decary A, Rouleau I, Montplaisir J. Cognitive deficits associated with sleep apnea syndrome: a proposed neuropsychological test battery. Sleep. 2000;23:1-13.

62. Engleman HM, Kingshott RN, Martin SE, Douglas NJ. Cognitive function in the sleep apnea/hypopnea syndrome (SAHS). Sleep 2000;23:102-108.

63. Carroll JL, McColley SA, Marcus CL, Curtis S, Loughlin GM. Inability of clinical history to distinguish primary snoring from obstructive sleep apnea syndrome in children. Chest. 1995;108:610-618.

64. Shpirer I, Elizur A, Shorer R, Peretz RB, Rabey JM, Khaigrekht M. Hypoxemia correlates with attentional dysfunction in patients with obstructive sleep apnea. Sleep Breath. 2012;16(3):821-827.

65. Aloia MS, Arnedt JT, Davis JD, Riggs RL, Byrd D. Neuropsychological sequelae of obstructive sleep apnea-hypopnea syndrome: a critical review. J Int Neuropsychol Soc. 2004;10(5):772-785.

66. Nagahama Y, Fukuyama H, Yamauchi H, et al. Age-related changes in cerebral blood flow activation during a Card Sorting Test. Exp Brain Res. 1997;114(3):571-577.

67. Torelli F, Moscufo N, Garreffa G, et al. Cognitive profile and brain morphological changes in obstructive sleep apnea. Neuroimage. 2011;54(2):787-793.

68. Canessa N, Castronovo V, Cappa SF, et al. Obstructive sleep apnea: brain structural changes and neurocognitive function before and after treatment. Am J Respir Crit Care Med. 2011;183(10):1419-1426.

69. Bedard MA, Montplaisir J, Richer F, Malo J. Nocturnal hypoxemia as a determinant of vigilance impairment in sleep apnea syndrome. Chest. 1991;100:367-370.

70. Naismith S, Winter V, Gotsopoulos H, Hickie I, Cistulli P. Neurobehavioral functioning in obstructive sleep apnea: differential effects of sleep quality, hypoxemia and subjective sleepiness. J Clin Exp Neuropsychol. 2004;26(1):43-54

71. Bédard MA, Montplaisir J, Richer F, Malo J, Rouleau I. Persistent neuropsychological deficits and vigilance impairment in sleep apnea syndrome after treatment with continuous positive airway pressure (CPAP). J Clin Exp Neuropsychol. 1993;15:330-341.

72. Ferini-Strambi L, Baietto C, Di Gioia MR, et al. Cognitive dysfunction in patients with obstructive sleep apnea (OSA): partial reversibility after continuous positive airway pressure (CPAP). Brain Res Bull. 2003;61:87-92.

73. Beebe DW, Groesz L, Wells C, Nichols A, McGee K. The neuropsychological effects of obstructive sleep apnea: a meta-analysis of normreferenced and case-controlled data. Sleep. 2003;26:298-307. 


\section{Publish your work in this journal}

Neuropsychiatric Disease and Treatment is an international, peerreviewed journal of clinical therapeutics and pharmacology focusing on concise rapid reporting of clinical or pre-clinical studies on a range of neuropsychiatric and neurological disorders. This journal is indexed on PubMed Central, the 'PsycINFO' database and CAS.

The manuscript management system is completely online and includes a very quick and fair peer-review system, which is all easy to use. Visit http://www.dovepress.com/testimonials.php to read real quotes from published authors.

\footnotetext{
Submit your manuscript here: http://www.dovepress.com/neuropsychiatric-disease-and-treatment-journal
} 